\title{
Review
}

\section{Radiation Therapy Induced Cardiovascular Disease}

\author{
Heath Adams, William Martin, Andrew M. Wilson, Sonny Palmer
}

Department of Cardiology, St Vincent's Hospital Melbourne, 41 Victoria Parade, Fitzroy 3065, Melbourne Australia

\begin{abstract}
Contemporary treatment modalities for malignancy including radiation therapy have led to improved survival. However treatment related complications manifesting later in life including cardiovascular disease has led to survivors exhibiting a lower long term survival rate, when compared to age matched controls. This narrative review will discuss the pathophysiology, risk factors, clinical presentation, management and preventative techniques related to radiotherapyinduced cardiotoxicity.
\end{abstract}

Key words: radiation therapy, cancer, cardiovascular complications

(Heart-Vessels and Transplantation 2017; 1: doi 10.24969/hvt.2017.25)

\author{
Abbreviations \\ BMS - Bare metal stents \\ CABG - Coronary artery bypass grafting \\ CVD - Cardiovascular disease \\ DES - Drug eluting stents \\ $\mathrm{HL}$ - Hodgkin's lymphoma \\ IMA - Internal mammary arteries \\ RIC - Radiotherapy-induced cardiotoxicity \\ $\mathrm{RR}$ - Relative risk \\ RT - Radiotherapy
}

\section{Introduction}

The advent of advanced hematological and oncological treatment modalities including radiation therapy (RT) has led to increased survival in patients with a range of malignancies. However, this increased curative and disease free survival rate has been offset by the development of late treatment related complications, such as secondary malignancies and cardiovascular disease. This would explain why childhood cancer survivors exhibit a long-term survival rate that is significantly lower than age and gender matched population controls. When compared to the general population, the lifespan of these patients may be reduced by up to 10 years (1). Similarly, in adult cancers, recent data demonstrates that the benefit of $\mathrm{RT}$ in breast cancer is attenuated by an increase in nonbreast cancer related mortality, including cardiovascular mortality (2).

Cardiovascular disease (CVD) is one of the leading causes of late mortality in pediatric patients treated with mediastinal radiation (3). Mediastinal radiation is used in the treatment of early breast cancer, Hodgkin's lymphoma ( $\mathrm{HL}$ ) and other malignancies that involve the thoracic region. It has deleterious effects on all tissues within the radiation field; mediastinal and sternal tissues, all layers of the heart, great vessels, valves, coronary arteries and the conduction system. This range of deleterious cardiovascular effects typically presents many years after the treatment period. These late effects, defined as medical complications occurring greater than five years after cancer treatment, significantly reduce the long-term survival of cancer patients (3).

Address for Correspondence: Heath Adams, Department of Cardiology, St Vincent's Hospital Melbourne, 41 Victoria Parade, Fitzroy 3065, Melbourne, Australia Email: hsladams@gmail.com

Received: 07.10.2017 Revised: 25.10.2017 Accepted: 26.10.2017 Copyright@ 2017 Heart Vessels and Transplantation 


\section{Pathophysiology}

Most manifestations of radiotherapy-induced cardiotoxicity (RIC) appear to be related to blood vessel damage. It is hypothesized that reactive oxygen species damage deoxyribonucleic acid strands with resultant activation of the inflammatory cascade. Progressive fibrosis in the interstitium of the myocardium ensues, with a reduced ratio of capillary to myocyte density and narrowing of the capillary and arterial lumens with subsequent myocardial cell death, ischemia and fibrosis $(2,4)$.

With respect to the coronary arteries, there is injury to the intima and development of atherosclerosis, replacement of damaged cells by myofibroblasts and deposition of platelets (4). In ApoE-/- mice murine models of atherosclerosis, exposure to ionizing radiation increased plaque inflammatory cell infiltrate and there was evidence of intra-plaque hemorrhage (5). In humans, the pathological features are similar to atherosclerosis except for the presence of medial thinning and adventitial fibrosis. Some animal studies suggest that radiation has a synergistic effect with other risk factors, such as hyperlipidemia, although this has not been clearly reproduced in humans. In porcine models using radioactive stents, medial thinning, adventitial fibrosis, intimal foam cell collections, calcification and necrotic core formation have all been observed $(6,7)$. Furthermore, it has been shown that irradiated arteries demonstrate endothelial dysfunction evidenced by impaired flow-mediated dilation, suggestive of impaired endothelial nitric oxide release, which may predispose to atherosclerosis and cardiovascular events (8).

The generalized fibrotic change affects all regions of cardiac tissue, with fibrosis and often calcification of the cardiac valve cusps and/or leaflets, the myocardium and conducting system as well as dense collagen and fibrin replacement of the pericardial fat leading to pericardial fibrosis and effusions (1, 9-12).

\section{Risk Factors}

Several treatment-related factors increase the risk of developing RIC. These consist of older treatment protocols, anteriorly weighted radiation fields, an absence of cardiac shielding, higher total radiation dose (greater than $40 \mathrm{cGy}$ in anthracycline naïve patients; greater than $30 \mathrm{cGy}$ combined with anthracycline treatment), dose per fraction and the combined use of anthracyclines (13).

It is now well established that radiotherapy has synergistic cardiotoxic effects with anthracyclines. When compared to controls, long term follow up of survivors following RT or chemotherapy demonstrate a relative risk of 15.1 (95\% Cl 4.8-47.9) for developing congestive heart failure, 10.4 (95\% Cl 4.1-25.9) for developing coronary artery disease (14), with a $7.9 \%$ cumulative incidence of heart failure and cardiomyopathy (15). The long-term cardiovascular effects of the new systemic agent, trastuzumab, a monoclonal antibody to the HER-2 growth factor receptor and the observation of synergistic cardiotoxic effects with anthracyclines needs evaluation (16). The use of the combined treatment regimen of cyclophosphamide, methotrexate and fluorouracil has also been implicated in the development of late cardiovascular complications (13).

There are also several patient related risk factors that predispose to a higher risk of delayed CVD in particular, younger age at the time of treatment and the presence of traditional cardiac risk factors such as smoking, diabetes, hypertension and hyperlipidemia $(3,13)$.

\section{Clinical Manifestations}

Many patients with RIC are asymptomatic and clinical manifestations are not apparent until decades after the initial exposure. With respect to coronary artery disease presentation, high dose mediastinal RT may cause a degree of autonomic denervation resulting in "silent" or atypical angina (11). Symptomatic patients present with the spectrum of CVD features; angina, dyspnea, fluid overload and syncope (11). In symptomatic patients, both atypical and typical clinical presentations pose a significant diagnostic challenge. The presenting symptoms may be due to one or a combination of coronary, valvular, myocardial and/or pericardial diseases (Table 1). Accordingly, thorough and detailed assessment with non-invasive imaging and invasive methods is essential. 
Table 1. RIC disease subtypes and clinical manifestations

\section{Cardiovascular Disease Subtype}

Coronary Artery Disease

Ves

Valvular Heart Disease

\begin{tabular}{|l|} 
\\
\hline Pericardial Disease \\
\hline Cardiomyopathy
\end{tabular}

Extra-cardiac manifestations

\section{Clinical Manifestation}

Angina or acute coronary

syndrome

Affects proximal vessels more common than distal vessels

Aortic and mitral pathology more common than right sided valves

Pericarditis

Pericardial effusion

Constrictive pericarditis

Restrictive cardiomyopathy

Dilated cardiomyopathy

(anthracyclines a risk factor)

Pulmonary fibrosis

Thyroid malignancy
Carotid stenosis

Superior vena cava

obstruction

RIC -radiotherapy-induced cardiotoxicity

The cumulative incidence of cardiac disease in survivors of $\mathrm{HL}$ rises from $2 \%$ at 5 years after treatment, to $23.2 \%$ at 25 years after treatment, with cardiovascular structures within the radiation field commonly affected (17). Hence, CVD secondary to RT represents a unique syndrome and the management of affected patients can be extremely challenging due to its diverse effects. Patients present with a constellation of cardiac and non-cardiac symptoms and signs related to proximal coronary artery disease, valvular dysfunction, conducting system disease, primary myocardial disease, pericardial disease, scarring and fibrosis of the proximal great vessels and other non-cardiac related organ involvement; thyroid dysfunction and radiation-induced lung injury (e.g. pulmonary fibrosis).

\section{Coronary Artery Disease}

The estimated prevalence of coronary artery disease developing after mediastinal RT is estimated to be in the order of $6-18 \%$ and typically occurs more than a decade after exposure and is often challenging to treat (18-21). In a study of 326 patients who survived $\mathrm{HL}$ and were treated with mantle RT at long-term follow-up, there was a $5.5 \%$ incidence of symptomatic cardiac disease including angina, myocardial infarction or cardiovascular death in a young group with a median age of 39.4 years (22). Aleman et al. (15) reported that RT increased the risk for myocardial infarction and heart failure two to seven-fold at a median follow-up of approximately 19 years in patients with a history of HL (15).

Patients with coronary artery disease secondary to RT tend to be younger than their counterparts (23). One study reports that the cumulative risk for ischemic heart disease for young adults treated with RT 20 to 25 years prior was $21.2 \%$ (95\% Cl 15-30) (24). Furthermore, six hundred and thirty five children and adolescents with a mean age of 15.4 years treated with high dose RT were followed for an average of 10.3 years. During this period, there were twelve cardiovascular deaths yielding a RR of 29.6 (95\% Cl 16-49.3), including nine who died from myocardial infarcts (RR $41.5,95 \% \mathrm{Cl}$ 18.1-82.1) $(25,26)$. Similar data have also been seen in survivors of non-seminoma testicular cancers treated with mediastinal irradiation (27). The relative risk tends to decrease with age, presumably as risk increases in non-irradiated patients (28).

From an anatomical perspective, coronary artery lesions in those patients treated with RT are more likely to be multiple and the stenoses typically involve the ostia or proximal portion of the vessel $(11,29)$. Two studies suggest that involvement of the left main coronary artery is more likely than in non-RT related disease (20, $31)$. This may explain the reason for sudden death in such patients $(11,29)$. 


\section{Valvular Heart Disease}

Patients with a history of mediastinal RT are also at increased risk of valvular heart disease. The degree of valvular dysfunction increases with time following RT with a statistically higher than expected rate of requiring surgical vale procedures at long term follow up $(32,33)$. Veinot et al. (34) have suggested that up to $80 \%$ of patients with radiation-induced heart disease showed valvular damage at autopsy. Similar results were seen by Brosius et al. (11) in an autopsy study of patients 15 to 33 years old.

Classically, the valve leaflets and cusps become markedly thickened, fibrotic and may even become calcified. There is often multi-valvular involvement irrespective of individual valvular disease severity. Regardless of the relative dose distribution, RT-induced valvular heart disease is more common in the aortic and mitral valve than the tricuspid and pulmonary valves (29). This is surprising given that the pulmonary valve lies most anterior and it raises the possibility that the progression of valvular pathology on the left hand side of the heart may be mitigated by the higher pressures in the systemic circulation. It is unknown when an asymptomatic patient will progress to symptomatic valvular heart disease. However, data demonstrates that diagnosis of asymptomatic valvular disease occurred at a mean of 11.5 years after irradiation compared with 16.5 years for symptomatic patients (35).

\section{Pericardial Disease}

Pericardial disease is a common manifestation of RTinduced CVD and the patient can present with pericarditis, pericardial effusion with or without constrictive physiology. Early pericardial effusions are common after mediastinal irradiation. Detailed clinical, non-invasive and invasive screening of 25 patients with $\mathrm{HL}$ (median 96 months later) showed that 16 had demonstrable significant pericardial disease of whom eight had symptoms (36). In one autopsy analysis radiation-induced pericardial disease of constriction, effusion or both was noted in $70 \%$ of cadavers (34). Veeragandham et al. (21) reviewed a small amount of previously available data on the prevalence of serious cardiac complications of mediastinal irradiation. This estimated the prevalence of cardiovascular complications, such as pericardial disease was 60 to $70 \%$, (mean time to onset of 1.5 to 4 years), and myocardial disease especially right ventricular dysfunction was 50 to $60 \%$ ( 3 years to onset). The interval from RT to symptom development ranges between 2 and 145 months with a mean of 58 months (34). Of these, the patients with pericardial effusions were more likely to present early whilst patients with constrictive pericarditis presented after 18 months (34).

\section{Cardiomyopathy}

In a large retrospective cohort study of cancer survivors treated before the age of 21 (pre 1986), survivors were more likely than their siblings to have heart failure (HR 5.9, $95 \% \mathrm{Cl} 3.4$ to 9.6; $\mathrm{p}<0.001$ ) (37). RT-induced cardiomyopathy is typically restrictive in nature with primarily diastolic dysfunction and normal to mildly reduced left ventricular ejection fraction.

In contradistinction, anthracycline-induced cardiomyopathy classically presents as a dilated cardiomyopathy with primarily systolic dysfunction and decreased left ventricular ejection fraction $(17,32,38$, 39). Thus, systolic heart failure is generally a consequence of combined modality therapy.

\section{Conduction System}

Involvement of the conducting system is common following RT (11). Right bundle branch block is common given the proximity of the right bundle to the endocardium and may be a consequence of direct injury from RT or indirectly from myocardial fibrosis and ischemia (32). The development of atrioventricular block has also been associated with mediastinal RT (4042). In a study of asymptomatic survivors after $\mathrm{HL}$ multimodality treatment (median follow up of 14.3 years), Adams et al. found that $75 \%$ of patients had evidence of conduction defects including complete heart block, chronotropic incompetence and resting tachycardia (38). A postmortem study demonstrated arteriosclerosis of the sinoatrial node, fibrosis of the atrioventricular node, as well as both bundle branches (42). Larsen et al. (12) also demonstrated increased frequency of corrected QT interval prolongation, supraventricular premature complexes, supraventricular tachycardia, ventricular premature complexes, couplets and ventricular tachycardia in series of children and young adults post anthracycline or mediastinal RT for a variety of cancers. 


\section{Extracardiac Vascular Manifestations}

The vascular effects of RT are not exclusive to the coronary tree with large arterial disease often seen, including common carotid and subclavian disease (43, 44). Head and neck irradiation has been associated with a high incidence of asymptomatic carotid disease (up to 40\%) (45), premature stroke and large vessel arterial disease $(46,47)$. Patel et al. (47) have reported in an extensive review of patients after therapy for $\mathrm{HL}$, non- $\mathrm{HL}$ and seminoma. They found 21 patients who developed disease in non-coronary arteries after treatment. The median time from irradiation to diagnosis of vascular stenosis was 15 years. Five patients died from complications related to their vascular disease, which included three deaths after stroke and two after small bowel infarction (46). RT-induced carotid disease is generally more extensive and involves longer segments of disease when compared with traditional carotid disease (48). Furthermore, great vein obstruction manifesting as superior vena cava syndrome has been reported out to 20 years after mediastina radiation (49).

\section{Prevention and Screening}

Cancer patients should have their cardiovascular risk factors assessed and managed prior to treatment and during treatment as per societal guidelines. Prevention of late cardiovascular effects and modification of treatment related risk factors is paramount. However, these measures should be carefully balanced against sufficient and necessary cancer therapy. Examples of treatment related risk modifications include chest shields, dose reduction, decreased field size and deep inspiratory breath holding during RT in particular for left sided breast cancer (3).

Screening cancer survivors for delayed cardiovascular effects is also of upmost importance, but may be challenging. Adams et al. (38) reported that 47 of 48 subjects had a cardiovascular abnormality discovered on screening. They also found that echocardiographic features of restrictive cardiomyopathy were common. The further recognition that radiotherapy induced coronary lesions may be clinically silent and present with advanced disease or cardiac death has led to recommendations that patients should be routinely screened for cardiovascular disease after undergoing mediastinal radiation therapy (50). However, as mentioned, screening is challenging in this group of patients. Co-existing pericardial, valvular, myocardial and/or pulmonary complications of radiotherapy may Heart-Vessels and Transplantation 2017; 1: doi 10.24969/hvt.2017.25 make performance or interpretation of non-invasive stress tests difficult. Cardiac stress testing may be occasionally limited by autonomic dysfunction and/or primary lung disease and thus target heart rates may not be achieved. Perfusion defects detected on Thallium-201 scintigraphy scanning are common after mediastinal irradiation. However, they do not necessarily correspond to the distribution of an epicardial artery and are suggestive of myocardial fibrosis or microvascular disease (51). Furthermore, abnormalities found on screening with Thallium 201 scintigraphy have not been associated with subsequent cardiac events (52).

\section{Diagnosis}

As well as standard investigations for ischemia and/or myocardial disease, there are several issues that need to be considered in patients with prior mediastinal RT. Firstly; the diagnosis of a single cardiac pathology does not obviate the search for other concomitant cardiovascular disease. Secondly, recurrent tumor or malignancy secondary to RT should also be considered and excluded if necessary, especially in patients presenting with pericardial effusion. Respiratory function testing and detailed imaging as well as thyroid function should be routinely performed in subjects presenting with dyspnea.

Patients who are asymptomatic should be followed up in a "Late Effects" or "Survivorship Clinic" at 5 years following the completion of RT, with initial cardiovascular examination, 12 lead electrocardiogram and transthoracic echocardiography observed by a supervising cardiologist. Consideration of 24-hour ambulatory electrocardiography monitoring and stress testing may be indicated depending on history and clinical findings (Table 2).

\section{Table 2. Screening clinical investigations}

12-lead electrocardiography

Transthoracic echocardiography

Exercise stress testing (if indicated)

24-hour ambulatory ECG monitoring (if indicated)

\section{Treatment}

Therapy for patients with radiotherapy associated ischemic heart disease remains challenging. It is expected that cases will continue to be seen as many of the younger patients treated in the 1970s and 1980s are now in middle age. 


\section{Medical Treatment}

Whether radiation-induced atherosclerosis relates to acceleration of atherosclerosis related to traditional cardiovascular risk factors or is in fact totally unrelated is not definitively known. To our knowledge, there is no prospective data on the efficacy of primary prevention for cardiovascular disease in this population. Nevertheless, it would seem reasonable to suggest that risk factors such as lipids and hypertension be carefully monitored and that a low threshold for preventive therapy be carefully considered, especially in patients older than 40 years of age. As discussed, echocardiographic screening is increasingly being performed. This will lead to earlier discovery of left ventricular dysfunction and should facilitate earlier therapy, however, again it should be noted that there is no prospective data to support this approach at this time.

Several agents have been investigated to reduce radiation-induced fibrosis, mainly in pre-clinical models (53). Interestingly, data has begun to emerge that blockade of the renin-angiotensin system may ameliorate radiation damage to the kidney (54). Whether angiotensin converting enzyme inhibitor use may specifically benefit or even prevent radiationinduced cardiac dysfunction is unknown in human studies but remains an interesting possibility. However, most patients seen by a cardiologist would have been treated many years previously, so prevention would likely need to be started at the time of radiation therapy. Several small studies have suggested that pentoxifylline may be of benefit in reducing radiationinduced fibrosis (55). In general, it appears reasonable to suggest that beta-blockers should be used cautiously, particularly in the presence of conducting system disease.

\section{Percutaneous Coronary Intervention}

The results of percutaneous treatment of coronary artery disease attributable to radiation therapy have been conflicting (56-58). Prior to the development of contemporary drug eluting stents, lesions treated with balloon angioplasty demonstrated progressive disease and restenosis $(56,59)$. There is very limited data relating to the use of stents to treat radiation-induced coronary disease (60-61) and almost no data on therapy for left main disease, which is commonly seen in radiation-induced coronary artery disease. Early data with bare metal stents (BMS) suggested high rates of restenosis, particularly in patients with impaired ejection fraction or small left main coronary arteries (62).

The advent of drug-eluting stents (DES) has led to further assessment of the possibility of treating left main disease percutaneously. Early data suggested that treatment of left main stenosis with DES was associated with a low 1-year mortality and is not associated with excess mortality at 1-year compared to coronary artery bypass grafting (CABG) in non-randomized studies (63, 64). Contemporary randomized data has confirmed non-inferior outcomes of left main disease treated with DES compared to CABG (65). From a technical perspective, bifurcation crush stenting of the distal left main artery with DES has been associated with higher major adverse cardiovascular events (66).

\section{Surgery}

\section{Access and Healing}

Radiation to the chest wall is associated with ulceration and can lead to myoskeletal necrosis. Although these occur much less frequently after mediastinal irradiation, surgical access and healing after sternotomy may be significantly impaired in patients who have received mediastinal irradiation. 


\section{Coronary Artery Bypass Surgery}

The use of CABG for the treatment of RT-induced left main disease was first described in the 1970's (67). Several issues related to radiation may complicate decisions for planned bypass surgery. These include coexistent pericardial, valvular, myocardial and/or pulmonary complications of radiotherapy. Although manageable, hypothyroidism may complicate the preoperative course of these patients. Tracheal complications can occur which are relevant in patients requiring intubation and/or prolonged ventilation with an endotracheal tube. Patients may have undergone previous thoracic operations relating to the primary tumor or other non-coronary disease such as valve replacement. Authors have suggested that operation may need to be deferred due to extensive pericardial and/or mediastinal fibrosis (31).

The internal mammary arteries (IMA) may be affected by radiation, however there is mixed data about the ability to use these as grafts in such patients. Some have suggested that IMA can be used safely in selected cases of patients with a history of thoracic radiation, with no increase in early graft failure (48). However, there are reports of IMA atherosclerosis or fibrosis when assessed pre-operatively, being associated with IMA failure (68). Although less common, successful combined procedures including CABG and valve replacement have been described (69).

Other important surgical issues described include the increased rate of early post-operative right ventricular dysfunction in up to $18 \%$ of patients and pulmonary complications, including difficulty with extubation related to pulmonary fibrosis (70). Authors have also commented on the importance of perioperative pacing in view of the high rate of conducting system disease and atrial stiffness in these patients (21).

\section{Valvular Disease}

Valvular dysfunction is often multi-valvular and often more than one valve needs definitive management. Earlier reports have shown that the operative mortality is high $(>50 \%)$ for valvular surgery in this context, although it varies between series (35). The reason for this greatly increased mortality is not definitively known, but most likely relates to comorbidities and preoperative complications arising specifically from the radiation damage and including technical difficulty in the operative field due to extensive fibrosis and poor healing and infection after the sternotomy (60).

\section{Pericardial Disease}

Patients may present with acute tamponade and some have suggested that pericardiocentesis alone without more definitive surgical treatment may not prevent all adverse outcomes, including death. Certain authors have recommended that pericardioectomy should be the treatment of choice in this situation, especially if another cardiac surgical procedure is being performed simultaneously. This is important as these patients have a high likelihood of requiring repeat sternotomies for subsequent cardiac complications from radiotherapy. Another consideration performing pericardioectomy is reducing the risk of constrictive pericarditis, which may be recurrent (21).

\section{Conclusion}

The management of patients with prior mediastinal radiotherapy represents a significant challenge due to the complex, extensive and multi-organ effects of mediastinal irradiation and the delay in the development of clinically significant disease. Although, significant heterogeneity exists in the clinical presentation, most patients will have features of radiation damage to some, if not all of the organs involved in the treated field. Therefore, clinicians evaluating these patients need to be aware of the full spectrum of likely effects and investigate these accordingly particularly prior to planned therapy such as surgery. This is critical as many features may not be clinically apparent and may complicate therapy. In order to facilitate early diagnosis and therapy, it seems reasonable to recommend that patients should be screened for cardiovascular disease and recurrent malignancy after mediastinal irradiation for an indefinite period. In the future oncologists, radiation oncologists and cardiologists must collaborate to minimize the cardiovascular adverse effects of life saving targeted therapies.

Peer-review: internal and external

Conflict of interest: None to declare

Authorship: H.A., W.M, A.M.W., and S.P. equally contributed to study and preparation of manuscript Acknowledgement and Funding: None to declare. 


\section{References}

1. Yeh JM, Nekhlyudov L, Goldie SJ, Mertens AC, Diller L. A model-based estimate of cumulative excess mortality in survivors of childhood cancer. Ann Intern Med 2010; 152: 409-17.

2. Hooning $\mathrm{MJ}$, Aleman $\mathrm{BM}$, van Rosmalen $\mathrm{AJ}$, Kuenen MA, Klijn JG, van Leeuwen. Cause-specific mortality in long-term survivors of breast cancer: A 25-year follow-up study. Int J Radiat Oncol Biol Phys 2006; 64: 1081-91.

3. Chen $\mathrm{MH}$, Colan SD, Diller L. Cardiovascular disease: cause of morbidity and mortality in adult survivors of childhood cancers. Circ Res 2011; 4; 108: 619-28.

4. Cuzick J, Stewart H, Rutqvist L, Houghton J, Edwards R, Redmond $C$, et al. Cause-specific mortality in long-term survivors of breast cancer who participated in trials of radiotherapy. J Clin Oncol 1994; 12: 447-53.

5. Stewart FA, Heeneman S, Te Poele J, Kruse J, Russell NS, Gijbels $M$, et al. lonizing radiation accelerates the development of atherosclerotic lesions in ApoE-/- mice and predisposes to an inflammatory plaque phenotype prone to hemorrhage. Am J Pathol 2006; 168: 649-58.

6. Virmani R, Farb A, Carter AJ, Jones RM. Comparative pathology: radiation-induced coronary artery disease in man and animals. Semin Interv Cardiol 1998; 3: 163-72.

7. Virmani R, Farb A, Carter AJ, Jones RM. Pathology of radiation-induced coronary artery disease in human and pig. Cardiovasc Radiat Med 1999; 1: 98-101.

8. Beckman JA, Thakore A, Kalinowski BH, Harris JR, Creager MA. Radiation therapy impairs endotheliumdependent vasodilation in humans. J Am Coll Cardiol 2001; 37: 761-65.

9. Hardenberg PH, Munley MT, Hu C, Hollis D, Light K, Blazing $\mathrm{M}$, et al. Doxorubicin-based chemotherapy and radiation increase cardiac perfusion changes in patients treated for left-sided breast cancer. Int J Radiat Oncol Biol Phys 2001; 51 (Suppl 1): S158 (Abstract).

10. Heidenreich PA, Hancock SL, Vagelos RH, Lee BK, Schnitter I. Diastolic dysfunction after mediastinal irradiation. Am Heart J 2005; 150: 977-82.

11. Orzan F, Brusca A, Gaita F, Giustetto C, Figliomeni MC, Libero L. Associated cardiac lesions in patients with radiation-induced complete heart block. Int J Cardiol 1993; 39: 151-6.

12. Larsen RL, Jakacki RI, Vetter VL, Meadows AT, Silber $\mathrm{JH}$, Barber G. Electrocardiographic changes and arrhythmias after cancer therapy in children and young adults. Am J Cardiol 1992; 70: 73-7.
13. Hooning MJ, Botma A, Aleman BM, Baaijens MH, Klijn JG, Taylor CW, et al. Long-term risk of cardiovascular disease in 10-year survivors of breast cancer. I Natl Cancer Inst 2007; 99: 365-75.

14. Oeffinger KC, Mertens AC, Sklar CA, Kawashima T, Hudson MM, Meadows AT, et al. Chronic health conditions in adult survivors of childhood cancer. $\mathrm{N}$ Engl J Med 2006; 355: 1572-82.

15. Aleman BM, van den Belt-Dusebout AW, De Bruin ML, van't Veer $\mathrm{MB}$, Baaijens $\mathrm{MH}$, de Boer JP, et al. Late cardiotoxicity after treatment for Hodgkin lymphoma. Blood 2007; 109: 1878-86.

16. Slamon DJ, Leyland-Jones B, Shak S, Fuchs $H$, Paton V, Bajamonde $A$, et al. Use of chemotherapy plus a monoclonal antibody against HER2 for metastatic breast cancer that overexpresses HER2. N Engl J Med 2001; 344: 783-92.

17. Galper SL, Yu JB, Mauch PM, Strasser JF, Silver B, Lacasce $A$, et al. Clinically significant cardiac disease in patients with Hodgkin lymphoma treated with mediastinal irradiation. Blood 2011; 117: 412-8.

18. Vlachaki MT, Ha CS, Hagemeister FB, Fuller LM, Rodriguez MA, Besa PC, et al. Long-term outcome of treatment for Ann Arbor stage 1 Hodgkin's disease: patterns of failure, late toxicity and second malignancies. Int J Radiat Oncol Biol Phys 1997; 39: 609-16.

19. Vlachaki MT, Hagemeister FB, Fuller LM, Besa PC, Hess $M A$, Brown $B$, et al. Long-term outcome of treatment for Ann Arbor Stage I Hodgkin's disease: prognostic factors for survival and freedom from progression. Int J Radiat Oncol Biol Phys 1997; 38: 593-9.

20. Wan SK, Babb JD. Radiation-induced stenosis of the left main coronary artery. Cathet Cardiovasc Diagn 1993; 28: 225-7.

21. Veeragandham RS, Goldin MD. Surgical management of radiation-induced heart disease. Ann Thorac Surg 1998; 65: 1014-9.

22. King V, Constine LS, Clark D, Schwartz RG, Muhs AG, Henzler $M$, et al. Symptomatic coronary artery disease after mantle irradiation for Hodgkin's disease. Int J Radiat Oncol Biol Phys 1996; 36: 881-9.

23. McReynolds RA, Gold GL, Roberts WC. Coronary heart disease after mediastinal irradiation for Hodgkin's disease. Am J Med 1976; 60: 39-45. 
24. Reinders JG, Heijmen BJ, Olofsen-van Acht MJ, van Putten WL, Levendag PC. Ischemic heart disease after mantlefield irradiation for Hodgkin's disease in longterm follow-up. Radiother Oncol 1999; 51: 35-42.

25. Hancock SL, Donaldson SS, Hoppe RT. Cardiac disease following treatment of Hodgkin's disease in children and adolescents. J Clin Oncol 1993; 11: 1208-15. 26. Hancock SL, Tucker MA, Hoppe RT. Factors affecting late mortality from heart disease after treatment of Hodgkin's disease. JAMA 1993; 270: 1949-55.

27. van den Belt-Dusebout AW, Nuver J, de Wit R, Gietema JA, ten Bokkel Huinink WW, Rodrigus PT et al. Long-term risk of cardiovascular disease in 5-year survivors of testicular cancer. J Clin Oncol 2006; 24: 46775.

28. Aleman BM, Russell NS, Bartelink H, van Leeuwen FE. Re: Radiation therapy in the treatment of Hodgkin's disease--do you see what I see? J Natl Cancer Inst 2004; 96: 235-6.

29. Brosius FC 3rd, Waller BF, Roberts WC. Radiation heart disease. Analysis of 16 young (aged 15 to 33 years) necropsy patients who received over 3,500 rads to the heart. Am J Med 1981; 70: 519-30.

30. Tenet W, Missri J, Hager D. Radiation-induced stenosis of the left main coronary artery. Cathet Cardiovasc Diagn 1986; 12: 169-71.

31. McEniery PT, Dorosti K, Schiavone WA, Pedrick TJ, Sheldon WC. Clinical and angiographic features of coronary artery disease after chest irradiation. Am J Cardiol 1987; 60: 1020-4.

32. Heidenreich PA, Hancock SL, Lee BK, Mariscal CS, Schnittger I. Asymptomatic cardiac disease following mediastinal irradiation. J Am Coll Cardiol 2003; 42: 7439.

33. Hull MC, Morris CG, Pepine CJ, Mendenhall NP. Valvular dysfunction and carotid, subclavian, and coronary artery disease in survivors of Hodgkin lymphoma treated with radiation therapy. JAMA 2003; 290: 2831-7.

34. Veinot JP, Edwards WD. Pathology of radiationinduced heart disease: a surgical and autopsy study of 27 cases. Hum Pathol 1996; 27: 766-73.

35. Carlson RG, Mayfield WR, Normann S, Alexander JA. Radiation-associated valvular disease. Chest 1991; 99: 538-45.
36. Pohjola-Sintonen S, Totterman KJ, Salmo M, Siltanen $P$. Late cardiac effects of mediastinal radiotherapy in patients with Hodgkin's disease. Cancer 1987; 60: 31-7. 37. Mulrooney DA, Yeazel MW, Kawashima T, Mertens AC, Mitby $P$, Stovall $M$, et al. Cardiac outcomes in a cohort of adult survivors of childhood and adolescent cancer: retrospective analysis of the Childhood Cancer Survivor Study cohort. BMJ 2009; 339: b4606.

38. Adams MJ, Lipsitz SR, Colman SD, Tarbell NJ, Treves ST, Diller L, et al. Cardiovascular status in long-term survivors of Hodgkin's disease treated with chest radiotherapy. J Clin Oncol 2004; 22: 3139-48.

39. Chen MH, Kerkela R, Force T. Mechanisms of cardiac dysfunction associated with tyrosine kinase inhibitor cancer therapeutics. Circulation 2008; 118: 84-95.

40. Tolba, KA and Deliargyris, EN. Cardiotoxicity of cancer therapy. Cancer Invest 1999; 17: 408-22.

41. Pohjola-Sintonen S, Totterman KJ, Kupari M. Sick sinus syndrome as a complication of mediastinal radiation therapy. Cancer 1990; 65: 2494-6.

42. Cohen SI, Bharati S, Glass J, Lev M. Radiotherapy as a cause of complete atrioventricular block in Hodgkin's disease. An electrophysiological-pathological correlation. Arch Intern Med 1981; 141: 676-9.

43. Andrieu JM, Jais JP, Colonna P, Desablens B, Briere J, Francois $S$ et al. Ten-year results of a strategy combining three cycles of ABVD and high-dose extended irradiation for treating Hodgkin's disease at advanced stages. Ann Oncol 1998; 9: 195-203.

44. Hassen-Khodja R, Kieffer E. Radiotherapy-induced supra-aortic trunk disease: early and long-term results of surgical and endovascular reconstruction. J Vasc Surg 2004; 40: 254-61.

45. Steele SR, Martin MJ, Mullenix PS, Crawford JV, Cuadrado DS, Andersen CA. Focused high-risk population screening for carotid arterial stenosis after radiation therapy for head and neck cancer. Am J Surg 2004; 187: 594-8.

46. Dorresteijn LD, Stewart FA, Boogerd W. Stroke as a late treatment effect of Hodgkin's disease. J Clin Oncol 2006; 24: 1480.

47. Patel DA, Kochanski J, Suen AW, Fajardo LF, Hancock SL, Knox SJ. Clinical manifestations of noncoronary atherosclerotic vascular disease after moderate dose irradiation. Cancer 2006; 106: 718-25. 
48. Cheng SWK, Ting AC, Lam LK, Wei WI. Carotid stenosis after radio therapy for nasopharyngeal carcinoma. Arch Otolaryngol Head Neck Surg 2000; 126; 517-21.

49. Lee $Y$, Doering $R$, Jihayel $A$. Radiation-induced superior vena cava syndrome. Tex Heart Inst J 1995; 22: 103-4.

50. Byrd BF 3rd, Mendes LA. Cardiac complications of mediastinal radiotherapy. The other side of the coin. J Am Coll Cardiol 2003; 42: 750-1.

51. Maunoury C, Pierga JY, Valette H, Tchernia G, Cosset JM, Desgrez A. Myocardial perfusion damage after mediastinal irradiation for Hodgkin's disease: a thallium201 single photon emission tomography study. Eur J Nucl Med 1992; 19: 871-3.

52. Girinsky T, Cordova A, Rey A, Cosset JM, Tertian G, Pierga JY. Thallium-201 scintigraphy is not predictive of late cardiac complications in patients with Hodgkin's disease treated with mediastinal radiation. Int J Radiat Oncol Biol Phys 2000; 48: 1503-6.

53. Moulder JE. Pharmacological intervention to prevent or ameliorate chronic radiation injuries. Semin Radiat Oncol 2003; 13: 73-84.

54. Moulder JE, Cohen EP. Future strategies for mitigation and treatment of chronic radiation-induced normal tissue injury. Semin Radiat Oncol 2007; 17: 141-8.

55. Okunieff $P$, Augustine E, Hicks JE, Cornelison TL, Altemus RM, Naydich BG et al. Pentoxifylline in the treatment of radiation-induced fibrosis. J Clin Oncol 2004; 22: 2207-13.

56. Handler CE, Livesey S, Lawton PA. Coronary ostial stenosis after radiotherapy: angioplasty or coronary artery surgery? Br Heart J 1989; 61: 208-11.

57. Sande LM, Casariego J, Llorian AR. Percutaneous transluminal coronary angioplasty for coronary stenosis following radiotherapy. Int J Cardiol 1988; 20: 129-32.

58. Nakhjavan FK, Yazdanfar S, Friedman A. Percutaneous transluminal coronary angioplasty for stenosis of the ostium of the right coronary artery after irradiation for Hodgkin's disease. Am J Cardiol 1984; 53: 341-2.

59. Khan $\mathrm{MH}$, Ettinger SM. Post mediastinal radiation coronary artery disease and its effects on arterial conduits. Catheter Cardiovasc Interv 2001; 52: 242-8.

60. Mert M, Arat-Ozkan A, Ozkara A, Aydemir NA, Babalik

E,et al. Radiation-induced coronary artery disease. Z Kardiol 2003; 92: 682-5.
61. Miltenyi Z, Keresztes K, Garai I, Edes I, Galajda Z, Toth L et al. Radiation-induced coronary artery disease in Hodgkin's disease. Cardiovasc Radiat Med 2004; 5: 38-43. 62. Takagi T, Stankovic G, Finci L, Toutouzas K, Chieffo A, Spanos $\mathrm{V}$ et al. Results and long-term predictors of adverse clinical events after elective percutaneous interventions on unprotected left main coronary artery. Circulation 2002; 106: 698-702.

63. Chieffo A, Morici N, Maisano F, Bonizzoni E, Cosgrave $J$, Montorfano $M$, et al. Percutaneous treatment with drug-eluting stent implantation versus bypass surgery for unprotected left main stenosis: a single-center experience. Circulation 2006; 113: 2542-7.

64. Park SJ, Kim YH, Lee BK, Lee SW, Lee CW, Hong MK, et al. Sirolimus-eluting stent implantation for unprotected left main coronary artery stenosis: comparison with bare metal stent implantation. J Am Coll Cardiol 2005; 45: 3516.

65. Stone GW, Sabik JF, Serruys PW, Simonton CA, Généreux $P$, Puskas J, et al. Everolimus-eluting stents or bypass surgery for left main coronary artery disease. $\mathrm{N}$ Engl J Med 2016; 375: 2223-35.

66. Valgimigli $M$, van Mieghem CA, Ong AT, Aoki J, Granillo GA, McFadden EP, et al. Short- and long-term clinical outcome after drug-eluting stent implantation for the percutaneous treatment of left main coronary artery disease: insights from the Rapamycin-Eluting and Taxus Stent Evaluated At Rotterdam Cardiology Hospital registries (RESEARCH and T-SEARCH). Circulation 2005; 111: 1383-9.

67. Ali MK, Kahlil KG, Fuller LM, Leachman RD, Sullivan MP, Loh KK, et al. Radiation-related myocardial injury. Management of two cases. Cancer 1976; 38: 1941-6.

68. Nasso G, Canosa C, De Filippo CM, Modugno P, Anselmi $A$, Gaudino $M$ et al. Thoracic radiation therapy and suitability of internal thoracic arteries for myocardial revascularization. Chest 2005; 128: 1587-92.

69. Mittal S, Berko B, Bavaria J, Herrmann HC. Radiationinduced cardiovascular dysfunction. Am J Cardiol 1996; 78: 114-5.

70. Annest LS, Anderson RP, Li W, Hafermann MD. Coronary artery disease following mediastinal radiation therapy. J Thorac Cardiovasc Surg 1983; 85: 257-63. 